\title{
Oil Tanker Simplified Fatigue Assessment with Inspection and Repair Approach and Parameters
}

\author{
Ozgur Ozguc
}

The occurrence of cracks in the hull structure of oil tankers is an important concern for the maritime industry because crack propagation will reduce collapse strength of deck-stiffened panels and, consequently, decrease the ultimate hull girder capacity of ship's structures. Fatigue is an important design criteria for ships to ensure a sufficiently high safety level. Fatigue life predictions of ship's structural details have traditionally been carried out using S-N approach and the Palmgren-Miner's rule. The principal objective of such approach is to estimate the time to failure in order to ensure a satisfactory design lifetime of ship's structural components. Potential cracks are considered to occur in the side shell, in the connections between longitudinal stiffeners and transverse web frame. The main objectives of the present study are to evaluate the fatigue life of vessel's amidships using the simplified fatigue method, which is based on DNVGLCG-0129 "Fatigue Assessment of Ship Structures" in order to determine the main cause of the observed cracks on the single

\section{KEY WORDS}

$\sim$ Fatigue assessment

$\sim$ Oil tanker

$\sim$ Longitudinal stiffeners connection

$\sim$ Crack propagation

$\sim$ Repair guidelines

Istanbul Technical University, Faculty of Naval Architecture and Ocean Engineering, Turkey

e-mail: ozguco@itu.edu.tr

doi: 10.7225/toms.v10.n01.003

This work is licensed under (cc) BY

Received on: Jul 9, 2020 / Revised on:Mar 15, 2021 / Accepted on: Mar 20, 2021 / Published: Apr 20, 2021 skin oil tanker. Fatigue assessment was based on worldwide trade. Longitudinal stiffeners at transverse frames amidships are considered. The results show that fatigue life is generally above 20 years; however, analysis has revealed that the fatigue life of typical stiffener transitions in the side shell is below 20 years. The fatigue lives of side shell longitudinals are regarded as normal for ships built in the period between 1980 and 1990 with extensive use of high tensile steel in the side shell. Inspection and repair proposals of details with fatigue lives below 20 years are advised accordingly. Findings of fatigue analyses provide remaining life assessment, inspection plan definition, determination of repair and modification solutions, and avoiding integrity issues resulting in production downtime and hot work or dry dock.

\section{INTRODUCTION}

The problem of fatigue has been very critical for ship owners, designer, and classification society. The assessment procedure for fatigue strength is a very complicated and time-consuming job, but for maintenance purposes, it is a very critical item (Ozguc 2017a, 2018a, 2020a). The fatigue damage of structural details of ships is of great importance in the shipbuilding industry as they can result in cracks that can jeopardize the structural integrity (2021). Ozguc (2017b) studied long-term loads and fatigue damage accumulation for various trading routes relative to North Atlantic operations based on IACS scatter diagram for a 216,000 m3 LNG vessel. Ozguc (2020b) studied the conversion of an oil tanker into FPSO to be operated in the Gulf of Mexico (GoM), considering fatigue simulations. The analyses covered a check of the longitudinal material amidships and were applied according to the approved drawings 'as measured' scantlings taken from UTM measurements. 
Recently, in the shipbuilding industry the value of fatigue strength verification has continued to grow. In particular, the verification of the fatigue strength at welded joints, structural discontinuities, etc. will take place during the initial design process for hull structures of the ship (DNVGL Rules for Classification Ships, 2020). Blagojević and Domazet (2002) provided a comparison between the simplified methods used by classification societies Bureau Veritas, Det Norske Veritas and Lloyd's Register of Shipping for the assessment of ship's structural components on a bulk carrier. Fatigue damage in combination with transverse structural elements is computed for a few longitudinals.

Lee (2013) performed the fatigue capacity for the structural connections such as supports and piping holes installed on the main deck, various supports for access inside the tanks and ladder supports for access inside the tanks. Det Norske Veritas (DNV) fatigue assessment procedure was employed that could be assessed more easily with some additional assumptions and idealizations. Parunov et al. (2013) studied the fatigue life of deck longitudinals of oil tankers. During the inspection of two tankers, long-term corrosion effects were modelled based on the regression equation fit for measuring thickness. A comparison was given of fatigue experiments performed using linear mechanics of fracture and S-N approaches.

The major classification societies have already published their fatigue evaluation notes. They discussed the "fatigue assessment of ship structures" in the DNV classification notes, which describes the fatigue assessment process and simplifies methods. Finally, the use of real ship data and reliability of the results were tested in the fatigue study performed by Chen et al. (2012).

In addition to stress ranges that include material type, average and residual stresses, fabrication factor including the quality and weld defects, and ultimately the size and thickness effects of the plate, Fricke (2017) discussed the factors affecting fatigue strength. Fatigue strength evaluation methods primarily used on ship structures were subsequently addressed such as $\mathrm{S}-\mathrm{N}$ approaches in accordance with the Palmgren-Miner rule for instance nominal, structural hot-spot approaches and notch stress approaches.

Garbatov et al. (2016) evaluated fatigue capacity and reliability assessment based on various local structures of the complex double-hull oil tanker vessels. Lotsberg (2019) has provided an overview of the evolution over the past 40 years of fatigue quality requirements for marine structures. The need for fatigue design of ship structures increased as more high-strength steel was being used in these structures during the 1970s.

A review of some recent developments on the aging effects of structural integrity of ships was provided by Jurišić et al. (2017). The paper deals with the application of non-linear finite element analysis as a suitable method for collapse assessment of uniaxial loaded plates and stiffened panels of vessel structures weakened by non-uniform corrosion degradation and fatigue cracks. Experimental studies were also reviewed to gain a better understanding of the recently found degradation of mechanical properties of corroded steel.

Corrosion and fatigue cracks are the most important degradation effects of ship structures. Both of the aging effects have strong implications for virtually all related failure modes such as rising stress levels and weakening of ship's structural strength. A very large crude oil carrier's corrosion-related impact on the ship's hull was investigated by Van and Yang (2017).

Yamamoto et al. (2018) evaluated the fatigue strength of welded joints in long life service as per calculations of corrosion fatigue crack propagation exposed to random loadings that followed an exponential distribution. Chichi and Garbatov (2019) investigated the efficiency in recovering the structural capacity of a double bottom side girder plate of an oil carrier, considering the probability of failure and cost associated with the retrofit of the plate. The Monte Carlo models were used for the nonuniformity of the corrosion degradation.

Ozguc (2020c) researched on the cyclic loads while drilling caused the initiation and growth of cracks in oil tubulars. It was discovered that the fatigue failure could have been caused by the cyclic load level and number of load cycles. Ozguc (2020d) aimed to focus on the comparison of fatigue damage capacity for side shell longitudinals under the effect of hull girder bending and pressure in combination. Fatigue assessment methods were considered components of stochastic and full spectral analysis of an FPSO vessel.

Ozguc (2020e) described fatigue analysis procedures supported by a developed tool to be used in the calculations. Three details of local fine mesh models such as deck erection butt weld, longitudinal stiffener through web-frame, and bottom erection butt weld were analyzed.

The main objectives of the present study are to evaluate the fatigue life of the vessel's midships using the simplified fatigue method based on DNVGL-CG-0129 "Fatigue Assessment of Ship Structures to determine the main cause of the cracks observed on the single-skin oil tanker. The fatigue assessment was based on worldwide trade. Longitudinal stiffeners at transverse frames amidships are considered. The results show that the fatigue life is generally above 20 years; however, the analysis has revealed that the fatigue life of typical stiffener transitions in the side shell is below 20 years. The fatigue lives of the side shell longitudinals are regarded as normal for ships built in the period between 1980 and 1990 with extensive use of high tensile steel in the side shell. Inspection and repair proposals of details with fatigue lives below 20 years are advised accordingly. 


\section{OVERVIEW OF OPERATIONAL CRACKS AND REPAIRS}

The fatigue calculations are carried out for a single oil tanker vessel with the main characteristics as listed in Table 1.

Table 1.

Vessel's main particulars.

\section{Description}

\section{Dimension}

\begin{tabular}{ll}
\hline Length between perpendiculars & $225 \mathrm{~m}$ \\
\hline Breadth moulded & $42.6 \mathrm{~m}$ \\
\hline Depth moulded & $19.6 \mathrm{~m}$ \\
\hline Draught (design moulded) & $13.7 \mathrm{~m}$ \\
\hline Displacement (fully loaded condition) & 104,059 (ton) \\
\hline Lightship weight & 15,541 (tons) \\
\hline Block coefficient & 0.81 \\
\hline Vessel service speed & 14 knots \\
\hline
\end{tabular}

Many cracks in the side shell were detected at the tripping brackets in both the cargo and ballast tanks. Figure 1 shows that the crack was initiated in the weld between the bracket toe and the stiffener flange. According to the operational information, most cracks were found in the side shell both in ballast and cargo wing tanks, and a few cracks were found in the longitudinal bulkhead at center cargo tank. The cracks in the side shell stiffeners propagated through the stiffener web and into the side shell plating. Further, the design shows that all tripping brackets in the side shell were welded with overlap to the side longitudinals. This increases stress concentration and reduces fatigue life significantly (up to $40 \%$ ).

Based on previous experience with large tripping brackets, large brackets represent large local stiffness. Relatively high stress concentration factors were found in the bracket toe and heel. Normally, the heel of brackets is the worst hot spot of oneside bracket details, but no cracks were discovered in the heel for the tripping brackets on this ship. Experience with tripping brackets on other vessels indicates that these details may crack in the toe as well as in the heel (Tanker Structure Co-operative Forum, 2011).

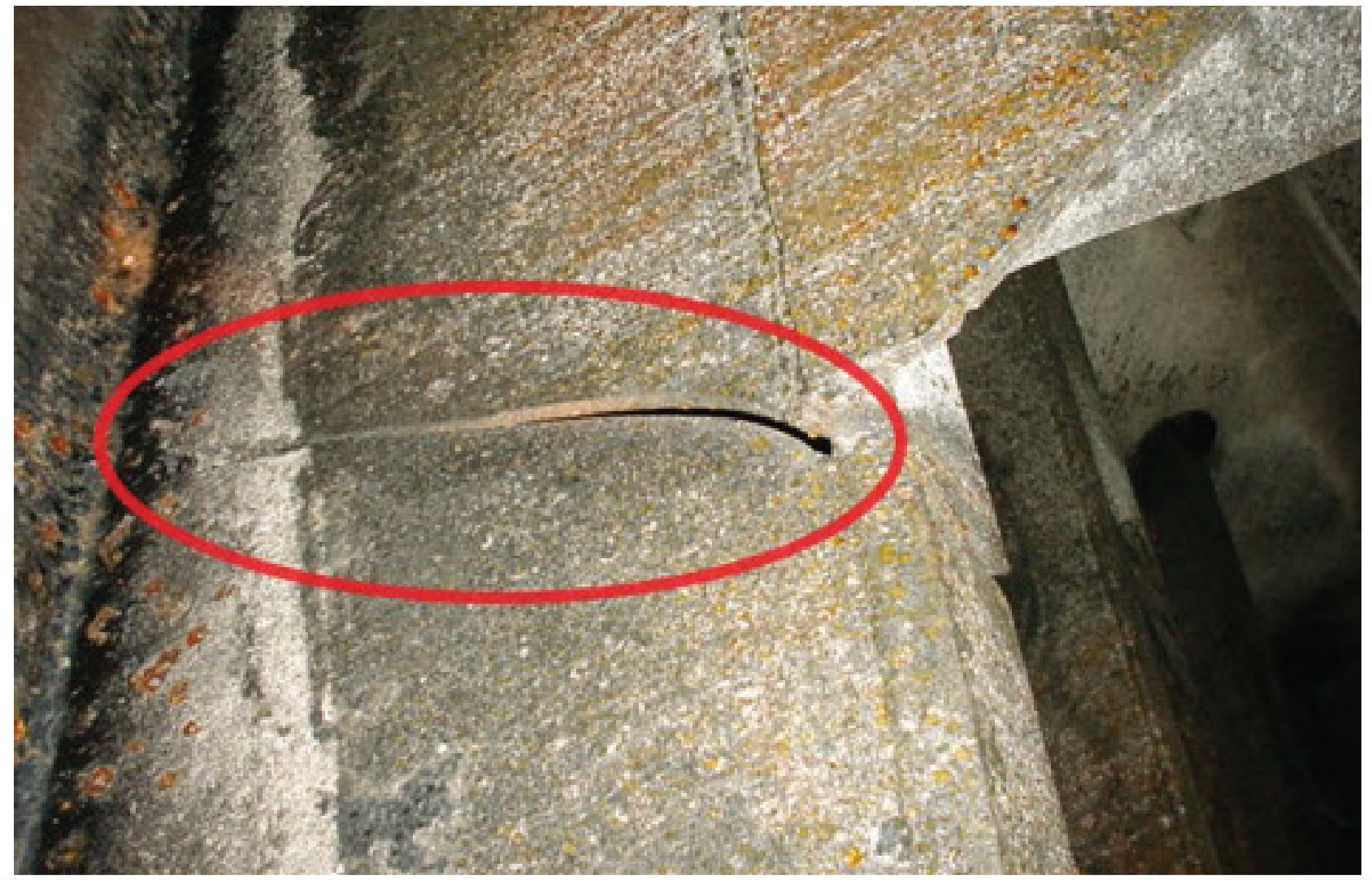

Figure 1.

A typical crack at the toe of the tripping bracket (Tanker Structure Co-operative Forum, 2011). 
A few tripping brackets in the side shell were repaired over the last two years. The longitudinal stiffeners were partly cropped out and renewed. New triangular brackets $(350 \times 350 \mathrm{~mm})$ were inserted at the bracket toes. The details that cracked are close to the neutral axis, and both vertical and horizontal bending moments will give small contributions. The lateral dynamic pressure is small as long as both the center cargo tank 7 and wing cargo tank 5 are either full or empty.

In the ballast wing tanks, cracks were identified in the slots at various locations. Figure 2 shows a crack below the stiffener flange between the stiffener web and the transverse web frame on the opposite side of the lug. Local corrosion is also evident from the picture and may give rise to corrosion fatigue in the base material. These web frames were partly cropped and renewed at the locations of the crack (longitudinal stiffener number L25). Cracks in the slots (at the web collar plates) were also found at other locations in the ballast tank, but these positions are not clearly specified. The web frames were partly cropped and renewed. Various cracks were identified and repaired over the past two years. The ship had been trading for around 19 years.

An overview of the cargo tanks and ballast tanks and the cross sections investigated is shown in Figure 2.

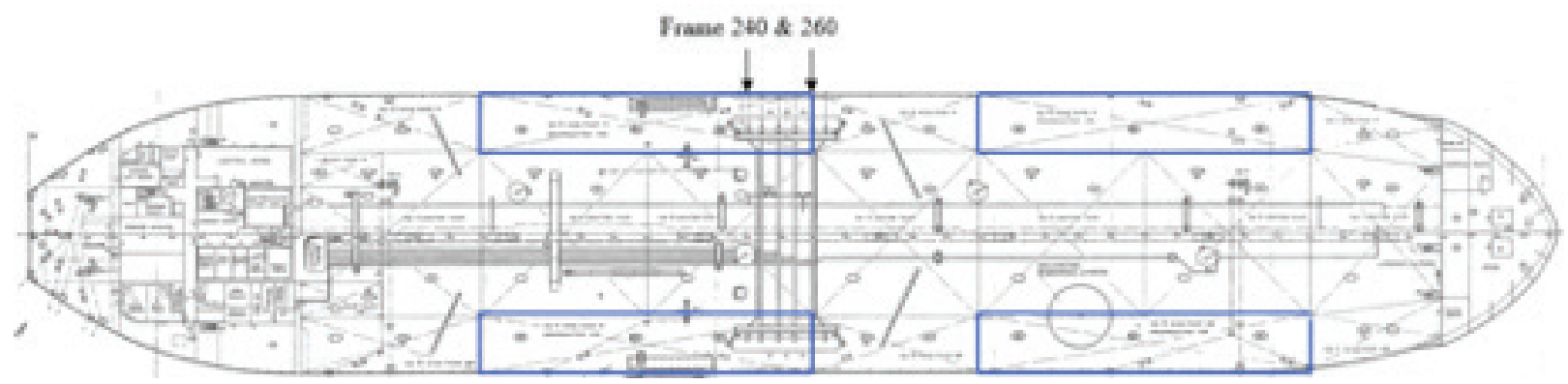

Figure 2.

Overview of cargo tanks (not marked) and ballast tanks (blue) and the cross-sections investigated. Frame 260 is a transverse bulkhead, while 240 is a typical frame.

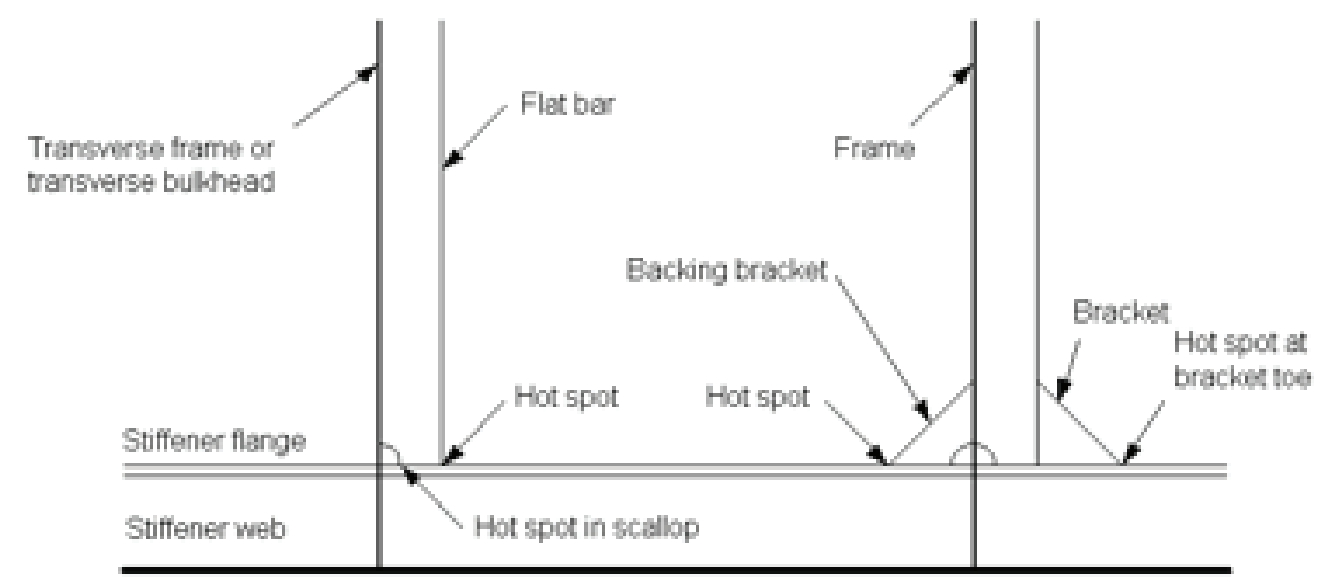

Plate

Figure 3.

Top view of a longitudinal stiffener in the side shell presenting typical hot spots. The plate refers to the side shell plating. The scallop is also referred to as the heel, while the other marked hot spots are referred to as the bracket toes (DNVGLCG-0129). 
Calculations were carried out by using the parametric formula according to DNVGL class guidelines (CG), Fatigue assessment of ship structures, Document code: DNVGL-CG-0129, and loading conditions. Normally, maximum loading and ballast condition may be used. The stress components were combined using correlation coefficients in order to take phase relations between the different loads into account. The coefficients are dependent on which loads are combined and the location of the stiffener. Stress concentration factors (SCF) were computed using parametric formulas taken from DNVGL-CG-0129 that includes typical transition details. The total SCF, K, is typically determined in the following way:

$K=K_{g} \cdot K_{w} \cdot K_{n} \cdot K_{e}$

where,

$K_{g}=$ Geometric SCF due to geometry of the detail.

$K_{w}=$ SCF due to the presence of a weld $\approx 1.5$ as default

$K_{n}=$ SCF due to skew bending of an L-profile (parametric formula)

$K_{e}=$ SCF due to an eccentricity, e.g. an overlap

The $\mathrm{K}_{\mathrm{g}}$ depends on type of loading; hence, $\mathrm{K}_{\mathrm{g}}$ from axial tension/compression may be different compared to $K_{g}$ from lateral pressure or relative deflection. $\mathrm{K}_{\mathrm{n}}$ is only included for lateral pressure (but could be relevant for axial tension in case of snipped stiffener flange). Typical locations are bracket toes and scallops, as shown in Figure 3.

\section{BASIC ASSUMPTIONS AND SIMPLIFICATIONS}

The most important assumptions and simplifications are given as follows:

- Wave environment for typical worldwide trade was applied.

- Zero mean stress was assumed, meaning that the mean stress reduction factor, $\mathrm{fm}$, was set to 0.85 . The mean stress reduction factor of 0.85 is an average value and was assumed to represent the actual condition.

- The cargo tanks were assumed uncoated.

- When the cargo tank is fully loaded condition, the tank is assumed to carry sweet crude oil $50 \%$ of the time (SN-curve in air) and sour crude oil $50 \%$ of the time (SN-curve for corrosive environment).

- When the cargo tank is empty crude oil washing is assumed. This gives corrosive environment $50 \%$ of the time (sour oil) and as in air $50 \%$ of the time (sweet oil).

- The ship is assumed to be in fully loaded condition $45 \%$ of the time, in ballast condition $40 \%$ of the time and in harbour condition (no fatigue damage contribution) $15 \%$ of the time

- Efficient coating for a period of 10 years was assumed in the ballast tanks since the coatings have been rated as "fair" (according to the ISO definition).
- The relative deflection was included at the transverse bulkhead at frame 260 .

- The fatigue calculation was based on the "as built" dimensions.

- An additional $\mathrm{K}_{\mathrm{e}}=1.15$ factor due to overlap of bracket on L-profiles was included.

- $\quad \mathrm{K}_{\mathrm{e}}$ is defined as additional stress concentration factor due to eccentricity tolerance (normally used for plate butt weld connections only).

- The non-linear splash zone (wet/dry zone) is accounted for.

- Density of oil was set to 0.91 tons $/ \mathrm{m}^{3}$ and water was 1.025 tons $/ \mathrm{m}^{3}$

The fatigue life in the present study is described as the crack initiation time such as crack starting to grow perpendicular to the main stress direction. This is less than the time it takes for a crack in the weld toe (the SN-curves used are valid for the weld toes) to grow through the thickness of the material. A crack may grow further before it is detected by visual inspection such as $100-200 \mathrm{~mm}$.

\section{OVERVIEW OF ACTUAL DETAILS}

The details considered in the present study represent the worst details with respect to fatigue for the current vessel. For clarification, the investigated details consist of a few basic connections.

For the tripping bracket in the bottom shell shown in Figure 4, the following SCFs are used:

Hot spot 1:

$K_{\text {axial }}=K_{g} \cdot K_{w}=2.1$

$K_{\text {bending }}=K_{g} \cdot K_{w}=2.4$ (lateral pressure)

Hot spot 2 (radius of $50 \mathrm{~mm}$ ):

$K_{\text {axial }}=K_{g} \cdot K_{w}=2.12$

$K_{\text {bending }}=K_{g} \cdot K_{w}=2.62$

According to the tabulated stress concentration factors (SCF) for tripping brackets given in DNVGL-CG-0129, the highest SCF is located in hot spot 2 . Hot spot 1 is given a reduced bending moment from lateral pressure. Maximum bending moment is used for hot spot 1 in the present study (based on experience with large tripping brackets in the finite element analysis). In addition, the crack is observed in the bracket toe instead of the heel. This means that the real SCF is larger at the toe than at the heel. Based on this, hot spot 2 is used to represent the fatigue life for the bracket toe. 
For the tripping bracket in the side, deck, and longitudinal bulkhead shown in Figure 5, the following SCFs are used:

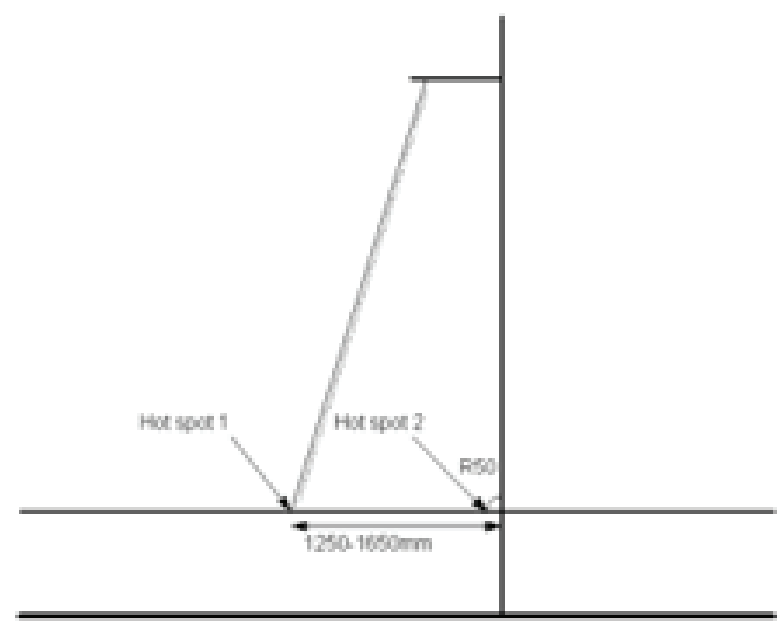

Figure 4.

Tripping bracket on top of T-profiles in bottom floors. The scallop is assumed with a radius of $50 \mathrm{~mm}$.

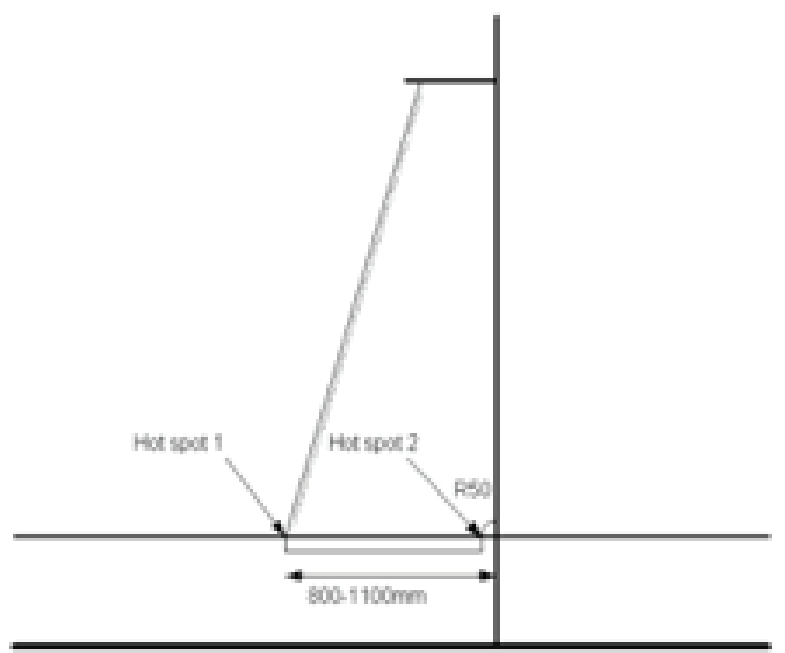

Figure 5.

Tripping bracket with overlap (L-profiles) located at deck, side and longitudinal bulkhead.

Hot spot 1:

$K_{\text {axial }}=K_{g} \cdot K_{w} \cdot K_{e}=2.1 \cdot 1.15=2.42$

$K_{\text {bending }}=K_{g} \cdot K_{w} \cdot K_{e}=2.4 \cdot 1.15 \cdot K_{n}=2.76 \cdot K_{n}$
Hot spot 2:

$K_{\text {axial }}=K_{g} \cdot K_{w} \cdot K_{e}=2.12 \cdot 1.15=2.44$

$K_{\text {bending }}=K_{g} \cdot K_{w} \cdot K_{e}=2.62 \cdot 1.15 \cdot K_{n}=3.02 \cdot K_{n}$

The $K_{n}$ factor depends on the L-profile dimensions and varies between 1.3 and 1.8 for the investigated details.

For the transition detail in side, deck, and longitudinal bulkhead shown in Figure 6, the following SCFs are used:

Hot spot 1:

$K_{\text {axial }}=K_{g} \cdot K_{w}=1.8$

$K_{\text {bending }}=K_{g} \cdot K_{w} \cdot K_{n}=1.8 \cdot K_{n}$

Hot spot 2:

$K_{\text {axial }}=K_{g} \cdot K_{w}=1.8$
$K_{\text {bending }}=K_{g} \cdot K_{w} \cdot K_{n}=1.8 \cdot K_{n}$

Hot spots 1 and 2 will have the same fatigue life and represent the same hot spot on two different frames. It should be noted that these SCFs represent the SCF in the web of the longitudinals and not the web frame scallops. The $K_{n}$ factor depends on the L-profile dimensions and varies between 1.3 and 1.8 .

The last detail is a common bracket detail. A detail without overlap typical for bottom longitudinals is presented in Figure 7. For the common bracket detail, the following SCFs are used:

Hot spot 1:

$K_{\text {axial }}=K_{g} \cdot K_{w}=2.1$

$K_{\text {bending }}=K_{g} \cdot K_{w} \cdot K_{n}=2.4 \cdot K_{n}$

Hot spot 2:

$K_{\text {axial }}=K_{g} \cdot K_{w}=2.12$

$K_{\text {bending }}=K_{g} \cdot K_{w} \cdot K_{n}=2.62 \cdot K_{n}$

For the details with overlap, the K-factors are multiplied with the factor of 1.15. The factors become the same as for the tripping bracket with overlap. The main difference is that the maximum stiffener bending moment is located $2 / 3$ of the length into the bracket. This means that the moment at the bracket toe is lower, where a reduction factor $r_{p}$ is used from DNVGL-CG-0129. Hot spot 2 then becomes significantly worse than hot spot 1. At 
the transverse bulkhead, double-side brackets are fitted in the side shell. In this case, hot spot 1 is located on the transverse bulkhead and hot spot 2 is located at the adjacent frame.

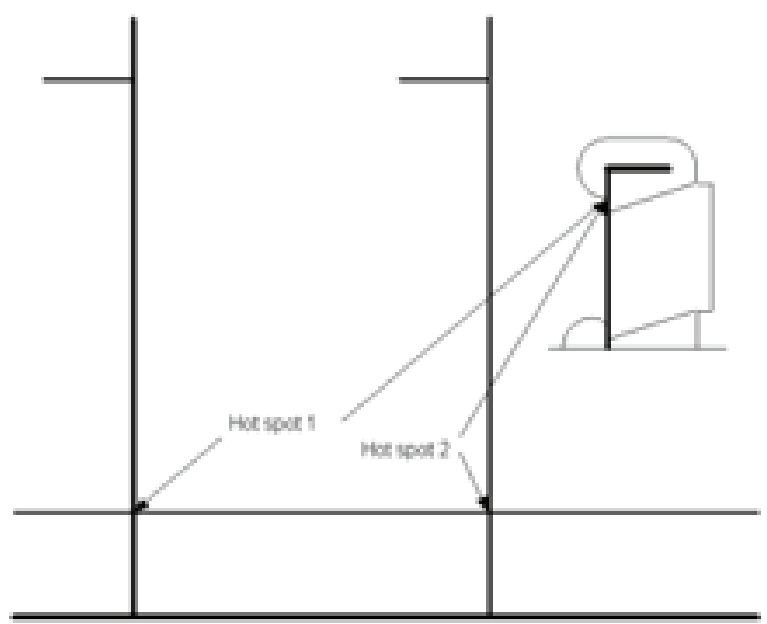

Figure 6.

Typical transition detail at deck, side, and longitudinal bulkhead.

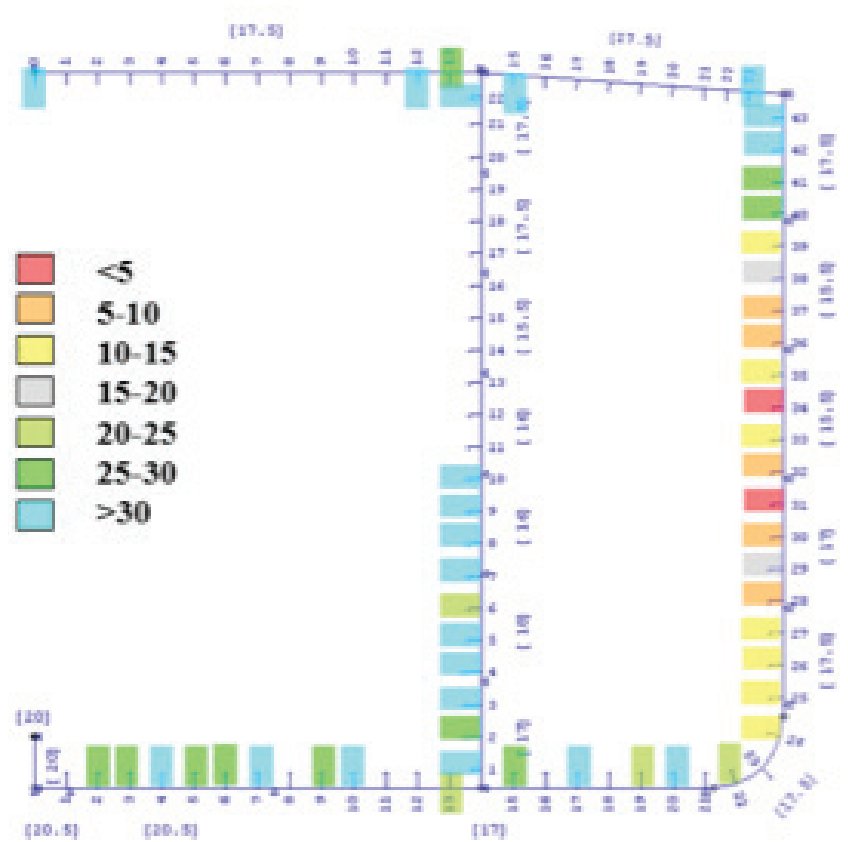

Figure 8.

Representative fatigue lives for frame 240 , representing a typical frame in the ballast wing tank amidships.

In some areas, only a few longitudinal stiffeners were investigated. The reason is that in these areas the calculations show that fatigue should not be a problem. Typically, the deck, bottom, and longitudinal bulkhead stiffeners have calculated fatigue lives above 20 years.

The fatigue lives in the side shell longitudinals are below 20 years. 20 years are normally regarded as a fatigue target life for new designs. Longitudinal L31 and L34 have fatigue lives below 5 years. These tripping brackets have already cracked at some locations. In addition, longitudinal L28, L30, L32, L36 and L37 have fatigue lives well below 20 years.

The external dynamic sea pressure is the dominant part in the fatigue life calculations of the side shell stiffeners. Other effects such as internal pressure and horizontal bending moment contribute to fatigue, but the main cause is the external pressure. The external pressure taking the dynamics in the splash zone (partly dry, partly wet area with the passing waves) into account gives the largest fatigue loads just below the still water line. In addition, the external pressure at the fully loaded condition contributes slightly more than the ballast condition to the fatigue lives in the side shell. The still water line for fully loaded condition is located approximately at L37. The fatigue life pattern shows a typical behavior when the external pressure dominates the fatigue damage. 
The fatigue life pattern is representative for single skin oil tankers, where high tensile steel is used in the ship's side and fatigue has not been assessed in the design process. The fatigue lives of the side shell stiffeners in the cargo wing tank amidships will be similar since the external pressure is dominating.

A fatigue life check of the side shell plating was performed. A rough estimate of the fatigue life for the plate at L31 (17-mm plate thickness and $900-\mathrm{mm}$ stiffener spacing) shows that fatigue life is above 30 years with a K-factor of 1.8 .

Frame 240 represents a typical frame, where relative deflection gives insignificant contribution to the fatigue damage. The transverse bulkhead at frame 260 was assessed in order to find out how much the relative deflection may contribute for these frames. There are no longitudinal stringers in the side shell, which indicates that the relative deflection between the transverse bulkhead and the adjacent frame may be significant. The frames also have only small flanges. Based on this, the transverse bulkhead at frame 260 was assessed. The details assessed are located in the cargo wing tank 3 forward of frame 260. Hot spot 1 is the bracket toe forward of the transverse bulkhead, while hot spot 2 is located at the heel of the bracket on frame 270.

The relative deflection effect was calculated based on formulas for double skin tankers. It was modified due to the configuration of the frame with large transverse deck and

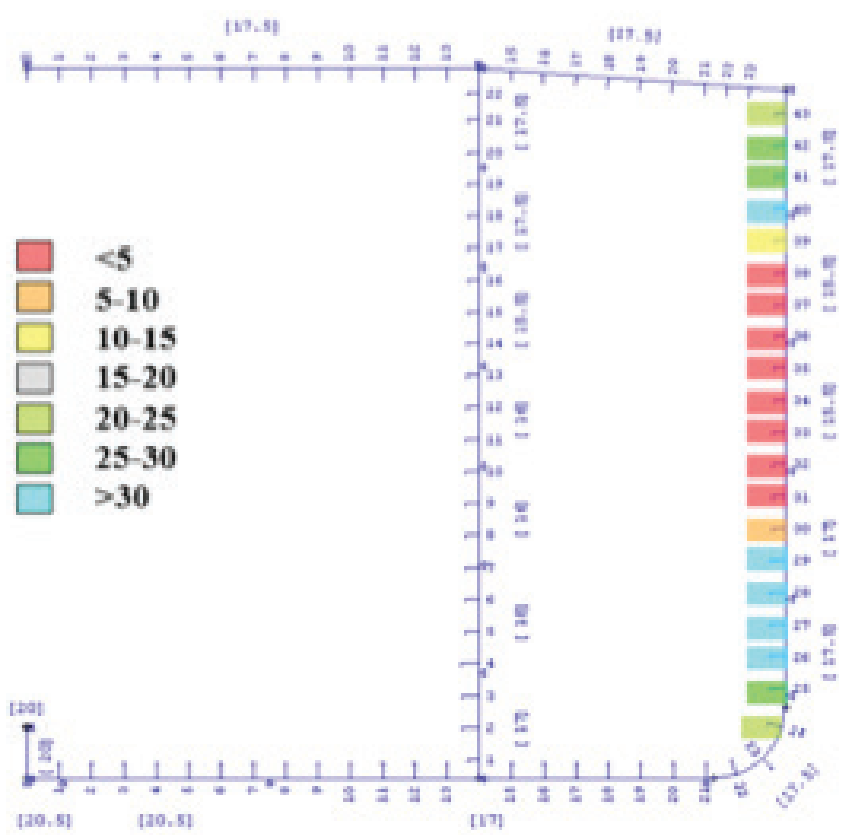

Figure 9.

Representative fatigue lives of stiffeners at the transverse bulkhead, frame 260 . Approximately the same fatigue lives are expected at the other transverse bulkheads. bottom girders. The relative deflection of side-shell longitudinals was then neglected for L29 and below, and L40 and above. In addition, relative deflection can be neglected due to a lack of lateral pressure in the deck and large transverse web frames in the bottom. The results presented in Figure 9 show that the relative deflection largely contributes to the fatigue damage in the side shell stiffeners. Both the external and internal pressure loads contribute to the accumulated fatigue damage. The fully loaded condition is much worse than the ballast condition in this case, and the fully loaded condition itself is sufficient to cause cracks at the transverse bulkhead even if the local design of the bracket details at the transverse bulkhead is better than at the web frames.

The bending effect of the transverse bulkhead due to an empty tank on one side and a full tank on the other side (or unsymmetrical details) makes the fatigue calculations more complex, and a finite element model is necessary to calculate this accurately. However, the fatigue lives found indicate that even if this is roughly assessed herein, the relative deflection effect is considerable at the transverse bulkheads. Cracks have already been repaired at these locations by fitting additional triangular brackets $(350 \times 350 \mathrm{~mm})$.

\section{REPAIRS IN PROPOSALS}

Repair proposals of different types of details are described. When considering repair proposals, one should bear in mind that the aim is to prevent severe cracking during the next 5 years of trade. Not all of the existing cracks will be found since most of them are undetectable at this stage and not all details will be inspected.

The way fatigue is normally handled is that the ship should follow the required surveys, and when cracks are identified, they should be repaired. Frequent surveys should be carried out to identify the first signs of cracks developing, and when cracks are detected, repairs should be carried out immediately, as described in this section. The repair proposals below are not a formal requirement, but should be treated as present study proposals for this particular vessel.

\section{THE STRUCTURAL DETAILS ALREADY REPAIRED}

Cracks have been found and repaired in the following ways: - Material is cropped and renewed.

- Material is cropped and renewed, and additional triangular brackets $(350 \times 350 \mathrm{~mm}$ ) are fitted to the existing bracket toes.

The principle of reinforcement by additional new triangular brackets at the old bracket toes is to move the hot spot to a new location, where the accumulated fatigue damage can start at zero. The other benefit is that the critical stress concentration factor is reduced at the new bracket toe due to the softening of 
the toe. The old hot spot, if not repaired, will have accumulated some fatigue damage, but the crack will grow or be initiated more slowly because of reduced stress levels.

\section{THE STRUCTURAL DETAILS TO BE SURVEYED}

The trade, and thereby the loading, are an uncertain quantity for the ship. The severity of the actual trade is difficult to determine without the full history, and the trade has large influence on the fatigue life. There are also some uncertainties to the quality of the coating and the accurate stress concentration factors of these different details (DNVGL Rules for Classification Ships, 2020). It is assumed that the ship was in service for about 19 years in worldwide trade and the future trade will remain the same. Based on the above, the present study proposes to do the following:

1. The weld should be evaluated visually with respect to possible crack locations and size/shape of the weld.

2. Close-up inspection by use of grinding followed by dye penetrant (DP) or magnetic particle inspection (MPI) should be performed for the critical details. This should be done since visual inspection may miss even cracks of considerable size.

3. The critical details are considered to be the details with fatigue life below 20 years (red, orange, yellow and grey boxes, as shown in Figures 8 and 9)

For the bracket toes, the inspection proposed is shown schematically in Figure 10. In principle, this will be the same for the brackets with overlap, as shown in Figure 11.

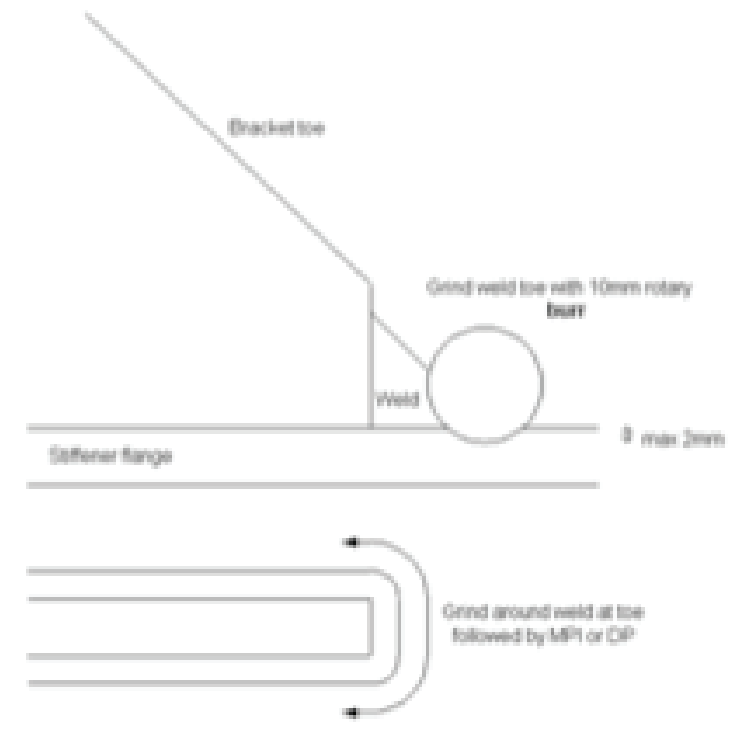

Figure 10.

Principle of bracket toe grinding followed by DP or MPI (IACS, 2017).

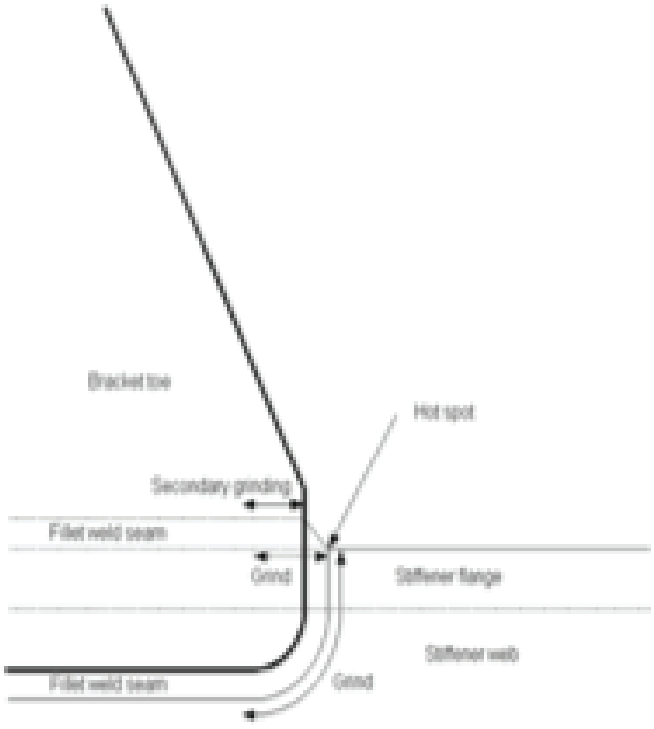

Figure 11.

Proposed grinding for bracket toes with overlap (IACS, 2017).

The crack may initiate in principle at three different locations as seen from Figure 12. It should be noted that the intention of the grinding above is to improve the fatigue life of the detail by removing the crack at location 1 . The grinding procedure may reduce the fatigue life at location 3 , while the fatigue life of location 2 will be unchanged. For the scallops the grinding is proposed as shown in Figure 13. Grinding of the scallops for brackets with overlap is similar as shown in Figure 14.

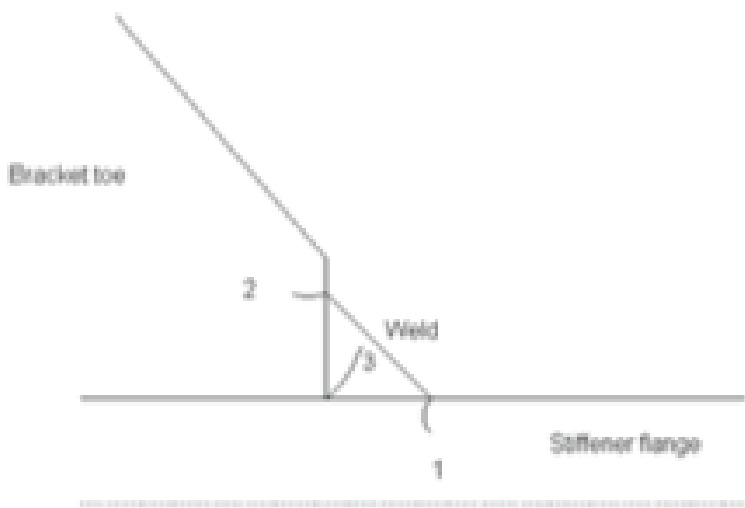

Figure 12.

Crack location of welds. 


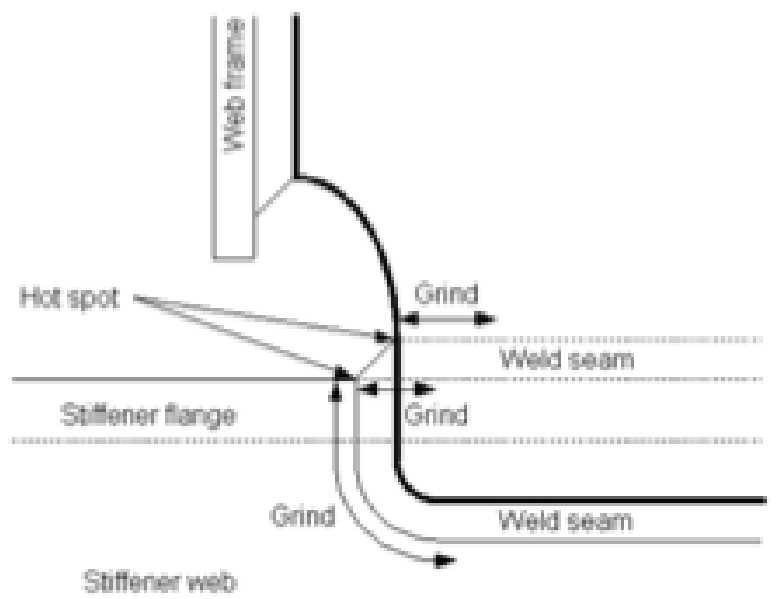

Figure 13.

Proposed grinding for scallops with overlap (IACS, 2017).
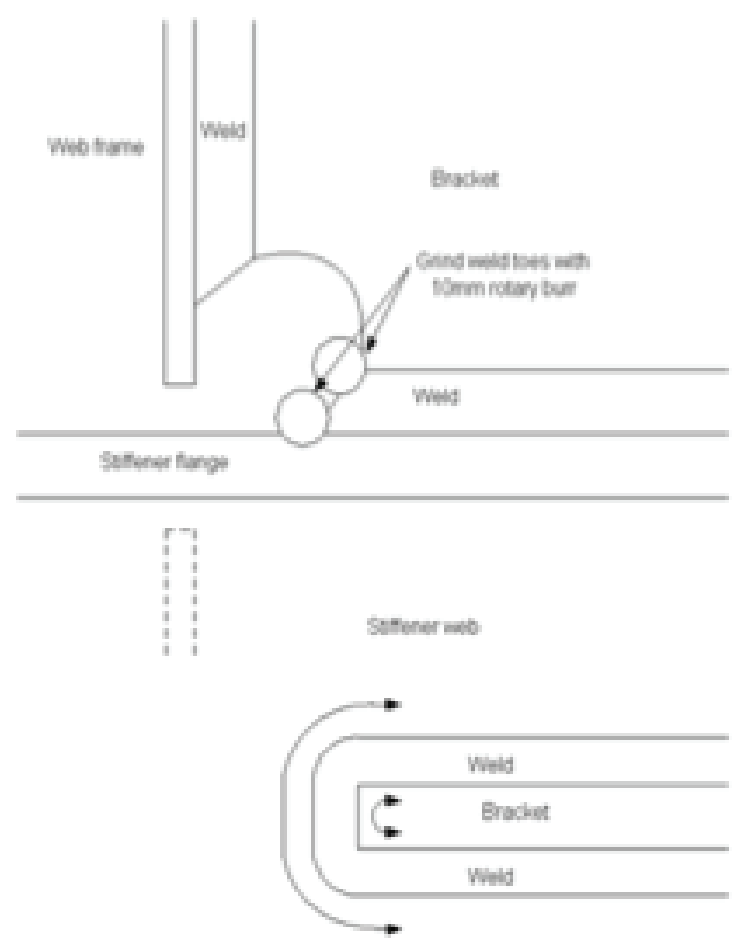

Figure 14.

Principle of grinding of critical weld toes in the scallops (shown with arrows), followed by DP or MPI (IACS, 2017).

The slots are more complicated. There are more hot spots, which might be critical depending on the design. In addition, the stress (principal stress perpendicular $\pm 45^{\circ}$ to the weld) makes contributions due to shear, bending, and skew bending of the stiffener and shear of the frame. Shear of the stiffener in combination with shear of the frame indicates that the longitudinals above the lower part of the vertical frames may induce the worst hot spots (IACS, Rec 47 Shipbuilding and Repair Quality Standard - Rev. 8 Oct 2017).

Based on the above, the slots should be checked for the details shown with grey, yellow, orange and red boxes, with special emphasis on the slots at the lower part of the web frame. For midship frames, special emphasis should be given to longitudinal L30 to L34 in the side shell. Typical hot spots to be checked are presented in Figure 15. This slot represents type "J" on the midship drawing, which seems to be a quite good detail except for hot spot 1 (denoted HS1) and hot spot 2. Hot spot 4 is of the recommended design used in order to move the stress flow away from the toe.

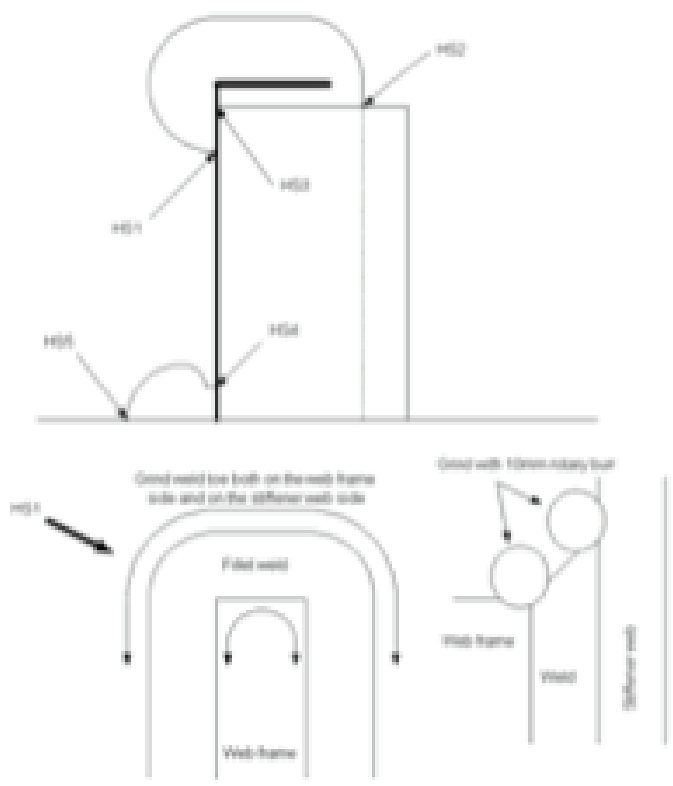

Figure 15.

Typical critical hot spots for slot of the "J" type.

Similarly, the slot of type " $\mathrm{H}$ " is also used in the critical areas. This is presented in Figure 16. Typically, HS1, HS2 and HS3 will be the worst. There are also a few other details of concern that were not investigated in the present fatigue analysis, but which may crack according to experience with similar vessels. The first detail is the bracket toe of the large brackets on the web frame, schematically shown in Figure 17. Hot spot HS2 will normally be the worst since it is exposed to the largest external pressure, but also the other three might be critical. The rest of the bracket toes in the frame are less critical.

The other type of detail is located at the longitudinal L4 in the bottom adjacent to the transverse bulkhead. This is a bracket 


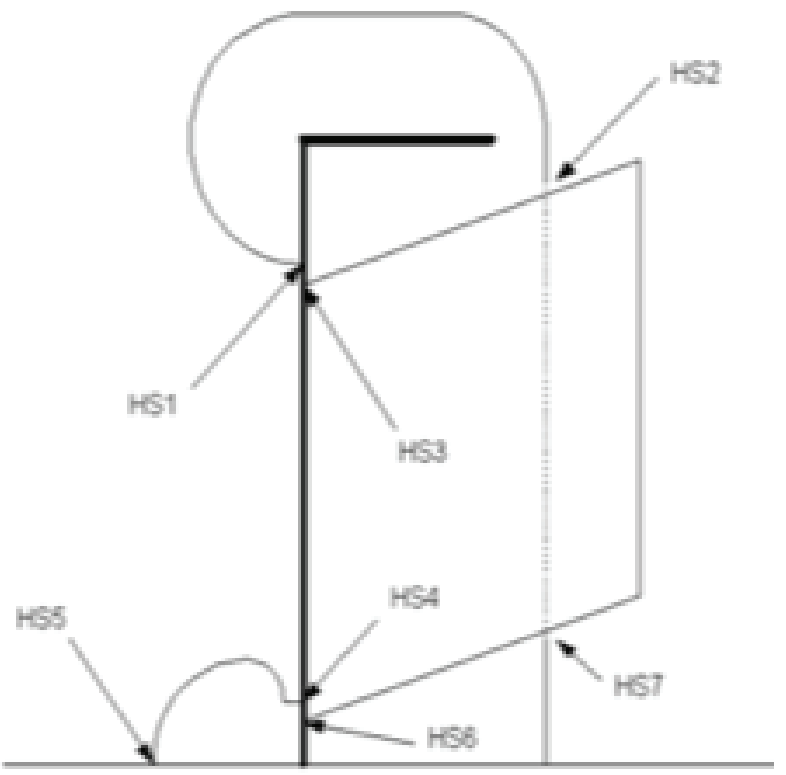

Figure 16.

Typical critical hot spots for the slot of " $\mathrm{H}$ " type.

toe detail exposed to relative deflection, as shown in Figure 18. The relative deflection effect is small for the bottom stiffeners; however, it is connected to a detail with significant longitudinal stiffness, hence these two effects make this detail probably the worst detail in the bottom. It is proposed to check the bracket toes at HS1 and HS2 at the transverse bulkhead, Frame 260.

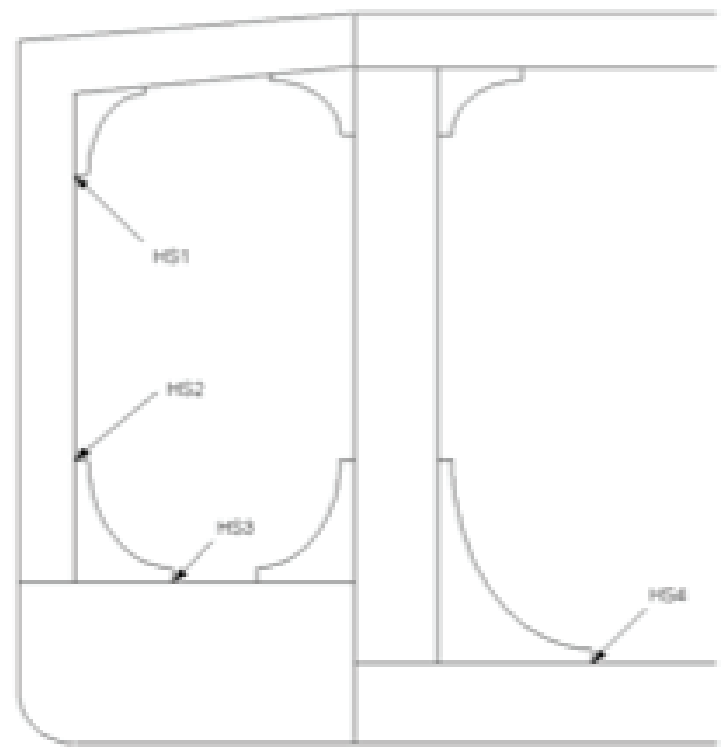

Figure 17.

Critical frame details of concern.

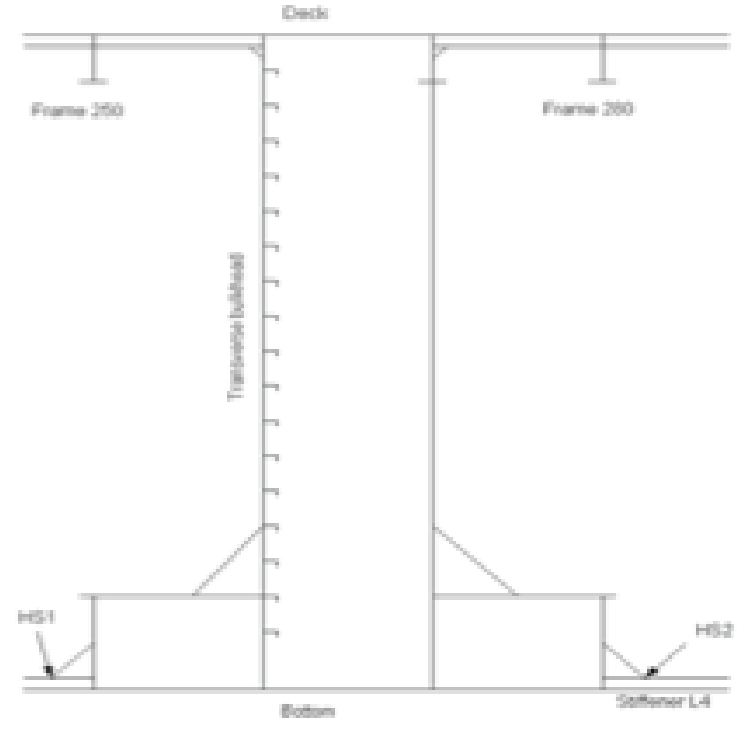

Figure 18.

Vertical girder at the transverse bulkhead and two critical details.

\section{GRINDING AND INSPECTION}

The grinding depth should be kept to a minimum to avoid reducing the strength of the weld and the surrounding material. One should make sure that the throat thickness is sufficient for grinding. The depth should be maximum $2 \mathrm{~mm}$ or $10 \%$ of the thickness, but it might be enough with $0.5 \mathrm{~mm}$ to $1 \mathrm{~mm}$ in order to perform DP or MPI. When an initial crack or undercut is observed, grinding should extend $0.5 \mathrm{~mm}$ below the bottom of any visible undercut. If the depth exceeds $2 \mathrm{~mm}$ or $10 \%$ of the thickness, repair welding is proposed (IACS, 2017).

MPI is preferred when practical for the different details since this procedure is more sensitive to cracks. Even cracks hidden down to $1 \mathrm{~mm}$ may be found by MPI. MPI and DP fail to identify the root failure of fillet welds. It is emphasized that coating is important after grinding or, else, the effect of grinding in a corrosive environment will be reduced to zero.

\section{REPAIR PROCEDURES IN PROPOSAL}

When cracks are found, they should be thoroughly recorded. The normal way is to refer to the frame number, longitudinal number, and indicate if the crack was found in the bracket toe, scallop or slot. For the purpose of experience feedback, verifying the crack cause, improving repair plans and inspection plans, the exact hot spot should be identified. When a crack is identified, the proposed repair is to gouge out the crack. Before welding, the gouged area should be cleaned by grinding $1 \mathrm{~mm}$ deep in 
order to remove slag effects. MPI should be performed again to make sure that the crack has been removed completely. The new weld is proposed with full penetration for bracket toes and scallops in order to avoid root failure. The throat thickness for fillet welds should be 3-5 mm larger in order to move the hot spot slightly away from the old hot spot, which might already be initiated and missed by the above mentioned procedure. Twopass welds should be used to get the wanted weld dimensions. The procedure is schematically shown for the slot in Figure 19.

If cracks at HS1 in the slot are a severe problem based on the inspection, an alternative procedure is to crop out some of

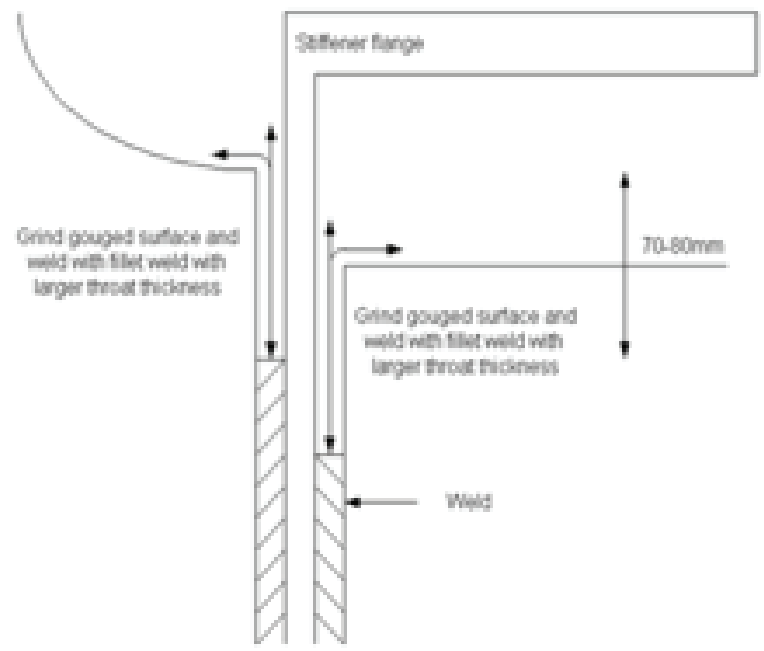

Figure 19.

Gouge, grind, and weld with larger throat thickness in order to restart fatigue life.

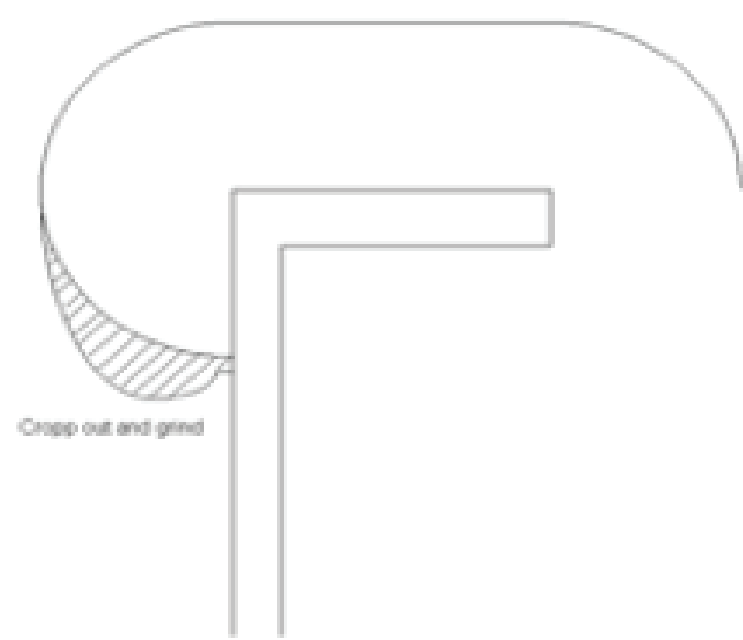

Figure 20

Improved slot design of a critical hot spot.

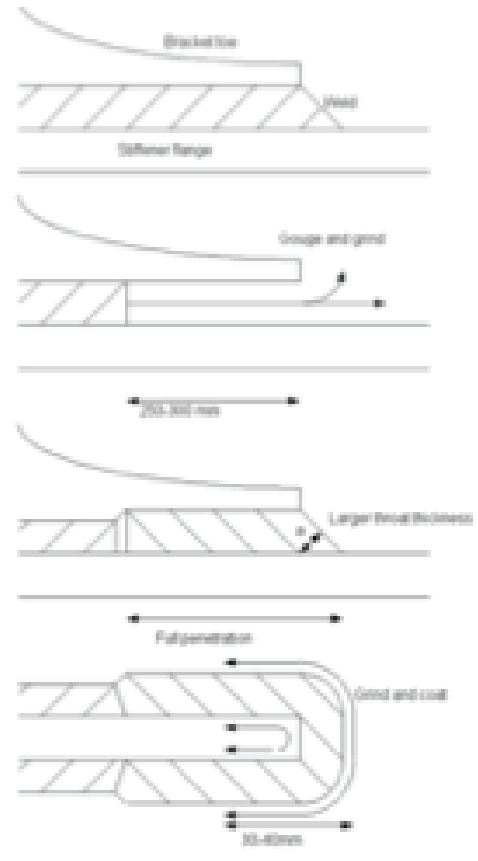

Figure 21.

Principle for resetting fatigue life of bracket toes and scallops. For brackets with overlap, fillet welds are used instead of full penetration (IACS, 2017).

the material and grind to improve the local design at the hot spot. Figure 20 presents an improved design of this detail. For thesehot spots, a small change in the design has a large impact on the fatigue life. Additional repairs as above may be necessary when cracks are found.

A similar procedure for the bracket toe is shown in Figure 21. It also shows that it is advised after welding to grind the weld toe and then coat. This will approximately double the fatigue life compared to not grinding after welding as long as coating is maintained. This procedure may be relevant for the critical details with the lowest fatigue lives such as L31 to L38 on the transverse bulkhead.

The previous repairs at the transverse bulkhead, frame 260 consist of fitting small $350 \times 350 \mathrm{~mm}$ brackets at the bracket toe. Fatigue life for these details may not be sufficient for the next 5 years. If cracks at the transverse bulkhead are a severe problem based on the inspection, an improved design of the brackets is proposed. The old brackets may be removed and new ones fitted. The improvement consists of a smooth bracket toe termination on both sides, as shown in Figure 22. It is preferred that also the backing bracket (on the other side of the bulkhead) is welded on top of the flange to avoid eccentricities. To ease fabrication, only two types of brackets may be used amidships even if the transverse horizontal bulkhead stiffeners are of different sizes (Tanker Structure Co-operative Forum, 2011). 

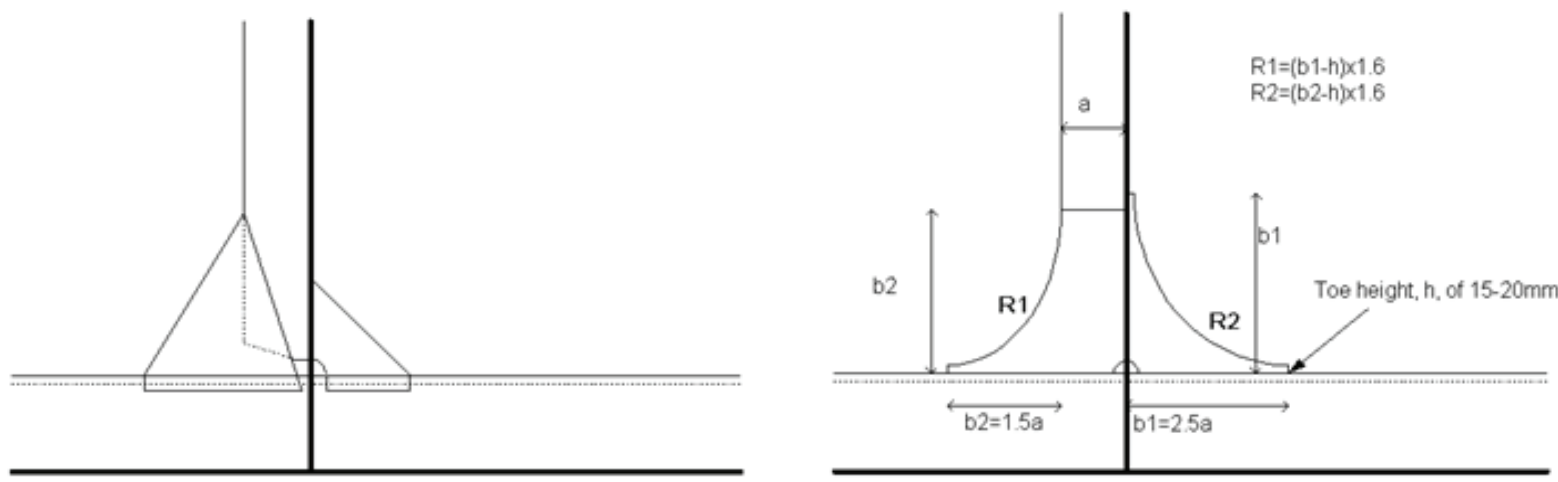

Figure 22.

Old bracket design above and new improved bracket design (Tanker Structure Co-operative Forum, 2011).

\section{CONCLUSION}

As fatigue failure can occur at very low stresses with little warning, this mode of failure is often overlooked in the design and the consequences are frequently catastrophic. Fatigue life predictions of ship's structural details have traditionally been performed by S-N method and the Palmgren-Miner's law. The findings of fatigue assessment are influenced by several aspects of cost and safety, including the quality of connection materials, quality of welding fabrication, frequency of inspections and repairs, consequences of potential fatigue failure, and residual strength of partially damaged structural systems.

The calculations resulted in fatigue lives below 20 years at the side shell longitudinals all along the vessel, while the bottom (with T-profiles) and deck have fatigue lives well above 20 years. The results are representative for single-skin oil tankers, where high tensile steel is used in the side shell without considering fatigue in the design phase. The remaining target fatigue life is defined to 5 years (i.e. 25-year-old vessel). The vessel has been in service for approximately 19 years, but the complete history of the trade is not available. It is indicated that the trade has been less severe than worldwide, upon which the calculations have were based. Based on the trade, with the prior reported inspection findings relating to crack history, it is proposed to thoroughly check the details with calculated fatigue lives below 20 years.

Based on experience, it is advised to inspect a few additional details. The first detail is located at the bracket toe in the lower part of the side shell frame. The second hot spot of concern is located at the bracket toe on top of bottom longitudinal L4 in connection with the vertical girder on the transverse bulkhead. In the process of seeking for cracks, grinding should be performed, followed by MPI or DP. MPI is preferred. When a crack is not found, the ground area should be coated. The remaining fatigue life should be sufficient. When a crack is found, the crack may be repaired in the following way: a) gouge the crack/weld, b) grind the gouged area for defects, slag, etc., and perform MPI again, c) weld with larger throat thickness and d) coat. The weld seam dimensions should be increased using two-pass (or more) welds. This will move the old hot spot and reset the fatigue life.

The cracks detected should be recorded and used as a decision for further work. For the tripping bracket design, additional triangular brackets of $350 \times 350 \mathrm{~mm}$ are found satisfactory for the remaining fatigue life. Modified design of the transverse bulkhead brackets has been proposed. For other details, resetting the fatigue life by gouging, grinding, welding and coating is found acceptable. Material that has been exposed to heavy corrosion, especially in fatigue critical areas such as the web frames around the slot, should be renewed. This should be based on the performed thickness measurements and inspections. It is emphasized that, in order to obtain the target fatigue lives, it is highly important to perform the repairs according to the best workmanship procedures.

\section{REFERENCES}

Blagojević, B. and Domazet, Ž., 2002. Simplified procedures for fatigue assessment of ship structures. In IMAM Congress.

Chen, T., Zheng, J. \& Bae, D.-M., 2012. A rapid estimation method of structural fatigue analysis for a $17 \mathrm{k}$ ton DWT oil tanker. Journal of Marine Science and Application, 11(2), pp.184-190. Available at:

http://dx.doi.org/10.1007/s11804-012-1121-6.

Chichi, D. and Garbatov, Y., (2019). Retrofitting Analysis of Tanker Ship Hull Structure subjected to Corrosion. Brodogradnja, 70(2), pp.87-109. Available at: http://dx.doi.org/10.21278/brod70205.

DNVGL class guidelines (CG), 2018. Fatigue assessment of ship structures, Document code: DNVGL-CG-0129, Edition 2018-01, Norway.

DNVGL Rules for Classification Ships, 2020. Part 3 Hull, Chapter 1 General principles, Edition - July 2020, Norway. 
Fricke, W., 2017. Fatigue and Fracture of Ship Structures. Encyclopedia of Maritime and Offshore Engineering, pp.1-12. Available at: http://dx.doi.org/10.1002/9781118476406.emoe007.

Garbatov, Y., 2016. Fatigue strength assessment of ship structures accounting for a coating life and corrosion degradation C. Rodopoulos \& A. de Jesus, eds. International Journal of Structural Integrity, 7(2). Available at: http://dx.doi.org/10.1108/ijsi-04-2014-0017.

IACS, 2017. Rec 47 Shipbuilding and Repair Quality Standard - Rev. 8 Oct 2017.

Jurišić, P., Parunov, J. \& Garbatov, Y., 2017. Aging effects on ship structural integrity. Brodogradnja, 68(2), pp.15-28. Available at: http://dx.doi.org/10.21278/brod68202.

Lee, K., 2013. Simplified fatigue guideline for deck opening and outfitting supports. Ships and Offshore Structures, 8(2), pp.154-162. Available at: http://dx.doi.org/10.1080/17445302.2012.701089.

Lotsberg, I., 2019. Development of Fatigue Design Standards for Marine Structures. Journal of Offshore Mechanics and Arctic Engineering, 141(3), p.031301. Available at: http://dx.doi.org/10.1115/1.4041993.

Ozguc, O., 2017a. Fatigue assessment of longitudinal stiffener end connections for ageing bulk carriers. Journal of Marine Science and Technology, 25(5), pp. 543-551.

Ozguc, O., 2017b. Evaluation of different trading routes on fatigue damage for a 216K m3 LNG carrier. Journal of Marine Science and Technol, 25(4), pp. 458-463.

Ozguc, O., 2018a. Simplified fatigue analysis of structural details of an ageing LPG carrier. Journal of Marine Engineering \& Technology, 17(1), pp.33-42. Available at: http://dx.doi.org/10.1080/20464177.2017.1282075.

Ozguc, O., 2018b. A new risk-based inspection methodology for offshore floating structures. Journal of Marine Engineering \& Technology, 19(1), pp.40-55. Available at: http://dx.doi.org/10.1080/20464177.2018.1508804.

Ozguc, O., 2020a. Procedures of Fatigue Analysis by Supporting Direct Load Application on Midship Sections. Transactions on Maritime Science, 9(1), pp.6-22. Available at:

http://dx.doi.org/10.7225/toms.v09.n01.001.
Ozguc, O., 2020b. Conversion of an oil tanker into FPSO in Gulf of Mexico: strength and fatigue assessment. Ships and Offshore Structures, pp.1-19. Available at: http://dx.doi.org/10.1080/17445302.2020.1790298.

Ozguc, O., 2020c. Analysis of fatigue behaviour of drill pipe on pin-box connection. Proceedings of the Institution of Mechanical Engineers, Part M: Journal of Engineering for the Maritime Environment, 235(1), pp.68-80. Available at: http://dx.doi.org/10.1177/1475090220950064.

Ozguc, O., 2020d. Fatigue assessment of FPSO hull side shell longitudinals using component stochastic and full spectral method. Applied Ocean Research, 101, p.102289. Available at: http://dx.doi.org/10.1016/j.apor.2020.102289.

Ozguc, O., 2021. Efficient fatigue assessment of the upper and lower hopper knuckle connections of an oil tanker. Proceedings of the Institution of Mechanical Engineers, Part M: Journal of Engineering for the Maritime Environment, 235(1), pp.110-126. Available at: http://dx.doi.org/10.1177/1475090220945460.

Parunov, J., et al., 2013. Fatigue Assessment of Corroded Deck Longitudinals of Tankers. International Journal of Maritime Engineering, 155(A1). Available at: http://dx.doi.org/10.3940/rina.ijme.2013.a1.246.

Tanker Structure Co-operative Forum, 2011. Outfitting related Structural Defects, Revision No: 0, March 2011.

Vu Van, T. \& Yang, P., 2017. Effect of corrosion on the ship hull of a double hull very large crude oil carrier. Journal of Marine Science and Application, 16(3), pp.334-343. Available at: http://dx.doi.org/10.1007/s11804-017-1425-7.

Yamamoto, N., Sugimoto, T. \& Ishibashi, K., 2018. Fatique Strength Assessment of a Structure Considering Corrosion Wastage and Corrosion Fatigue. Volume 3: Structures, Safety, and Reliability. Available at: http://dx.doi.org/10.1115/omae2018-78188. 